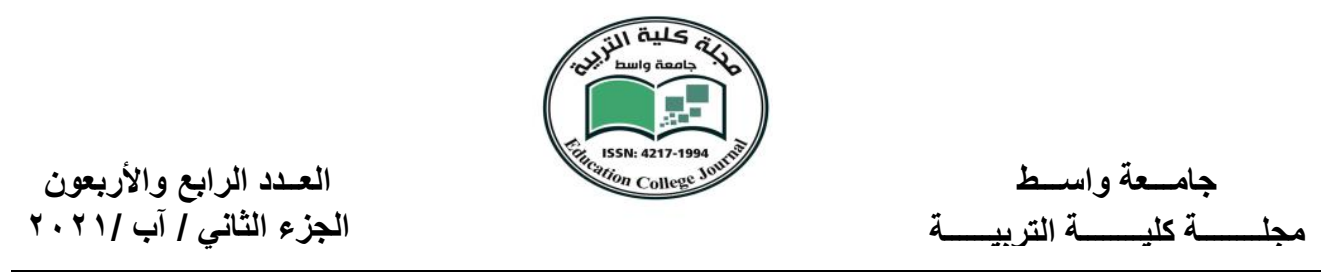

التّركيب الفعلي في ثلاثيّة نجيب محفوظ

الباحث: أحمد عبد السادة عبيد

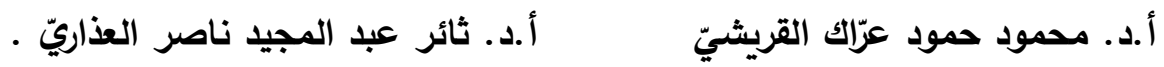

جامعة واسط / كلية الترّبية / قسم اللّغة العربية .

Abdalsadt46@gmail.com

الخلاصة

وقف البحث على التّركيب الفعلي ومكوناته، مع التطبيق على بعض النصوص من ثلاثيّة

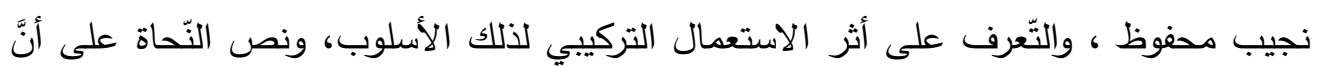

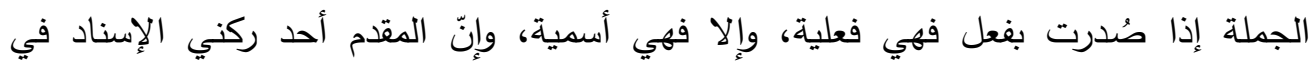
التركيب، وإنَّ الجملة التي صَدرها فعل في الأصل هي جملة فعلية سواء تقدم أم تأخر .

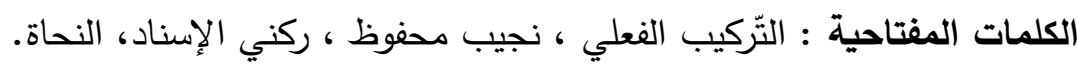

\title{
Construction of non_ordic
}

Ahmed Abdel Sada

: prof.Dr.mahmoud Hamoud Arak AlQuraishi

Prof .Dr. Thaer Abdel majid Nasser Ah_Adhiri.

Wasit university, college of Education, Arabic language section

\section{Abstract}

Stopping the research on .non_ordic construction which is not required but is obtained at the time of demand with represent ation on some compositions from the famouse Naguib Mahfouz trilogy and to identify the impact of the compositional use of these texts.

لقد اعتمد النّحاة القدماء على أنَّ الجملة إذا صدرت بفعل فهي فعلية، وإلا فهي اسمية

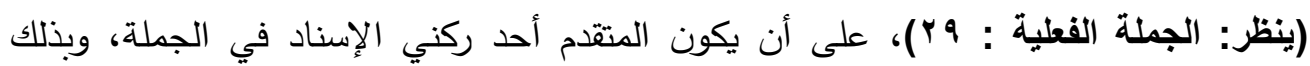

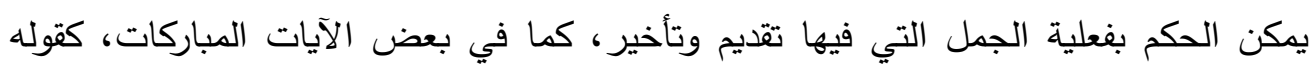

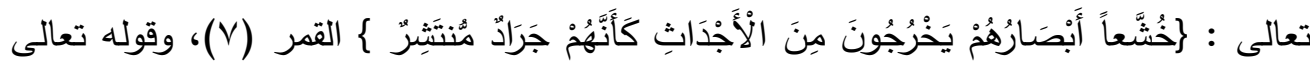

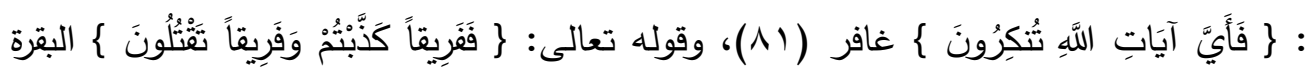




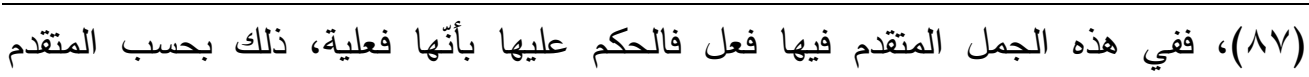

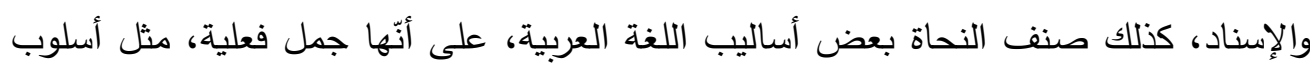

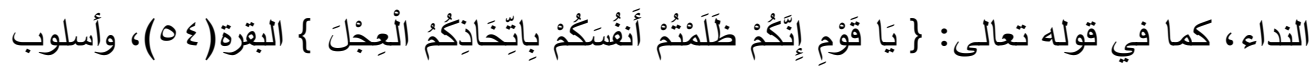

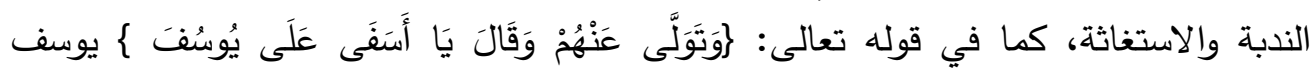

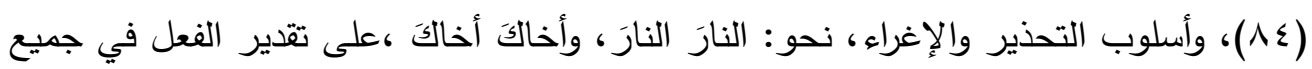
تلك الجمل (ينظر : الجملة الفعلية : . ب). وذهب ابن هثام الأنصاري في مغني اللبيب إلى أنَّ الجملة الفعلية هي: "التي صدرها

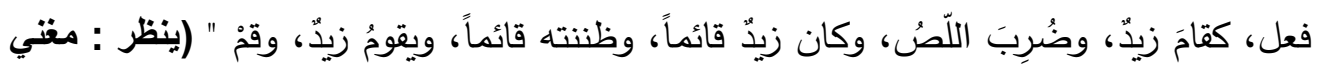

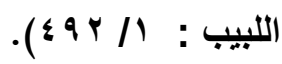
أيضا اعتمد ابن هشام في تصنيف الجملة على الإسناد في صدر الجملة، وعنده لا عبرة

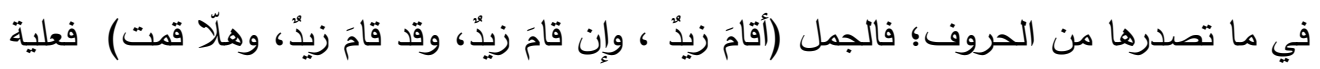

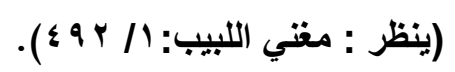

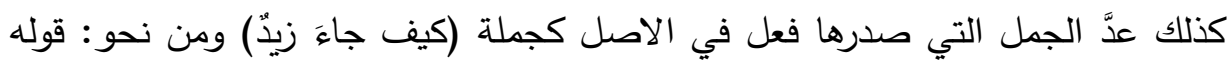

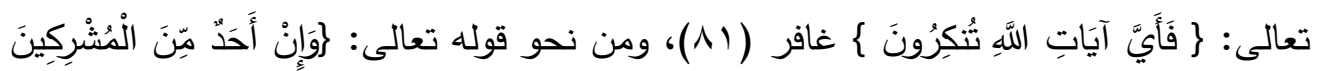

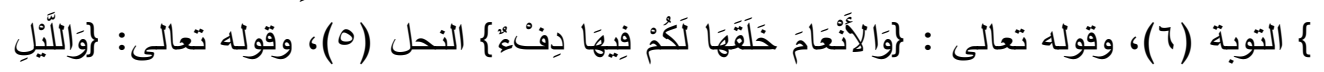

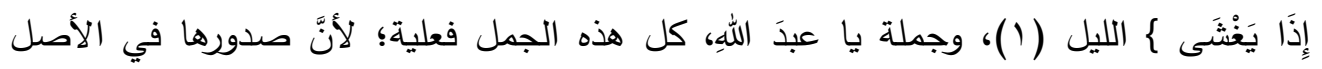

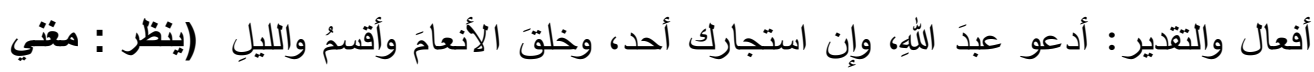

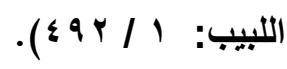

ويرى بعض النحاة، أنَّ ثمة إشكالاً في التصنيف أعلاه، التصنيف على أساس الإسناد

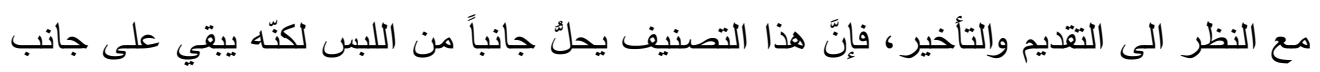

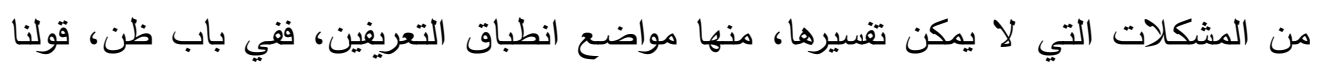

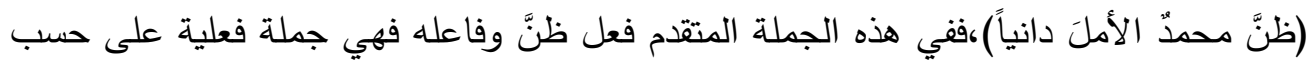

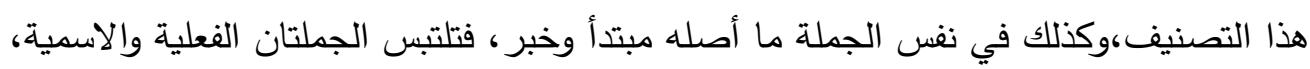
وبحسب التحليل اللغوي للنص لا يمكن الخلط بين الجملتين، وأيضا بحسب القاعدة التي تقول: الزيادة في المبنى تدل على زيادة في المعنى، في حين عند فصل جملة الفعل والفاعل الفعلية 
العـدـد الرابع والاربعون

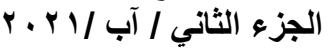

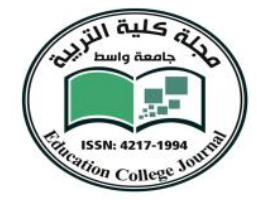

تبقى جملة، (الأمل دانيا) وهي أسمية حيث لا شبهة في التمييز بين الفعلية والأسمية في

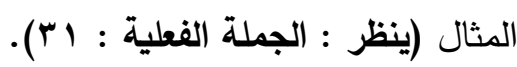

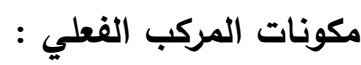

أ- الفعل: يعرف سييويه الأفعال بقوله :"أمثلة أُخذتْ من لفظ أحداث الأسماء، وبُنيتْ لما

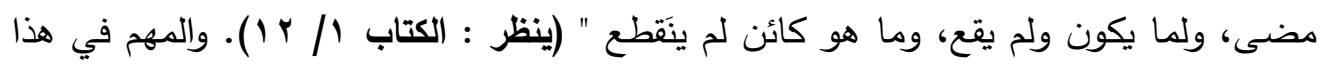

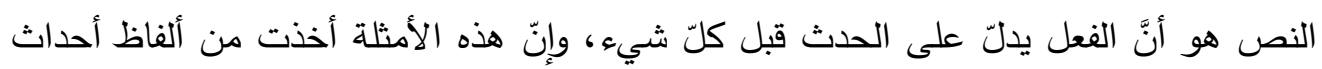

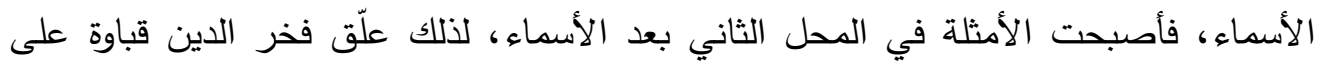

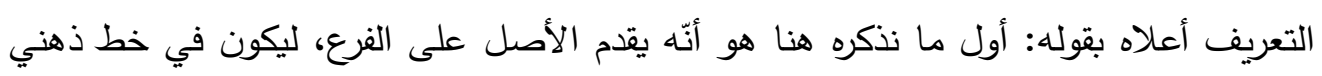

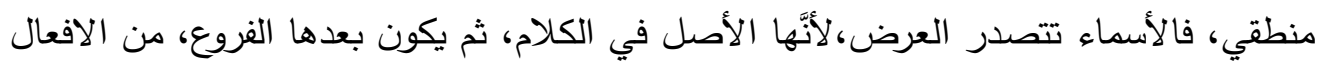

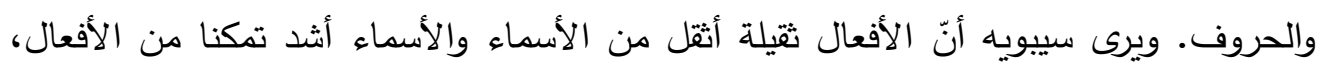

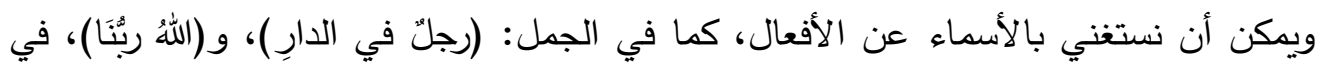

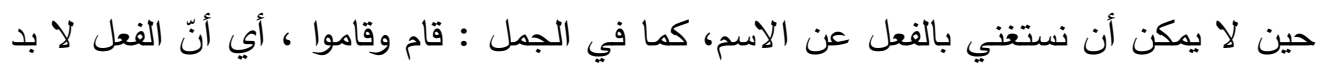

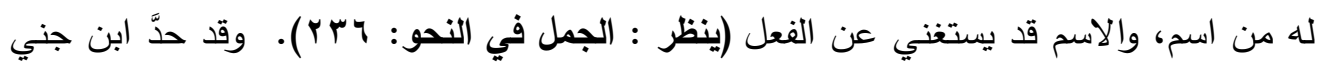

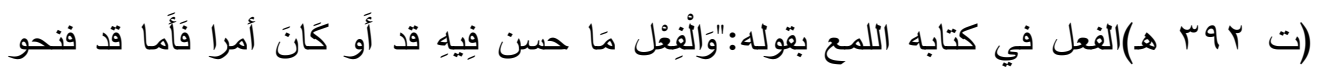

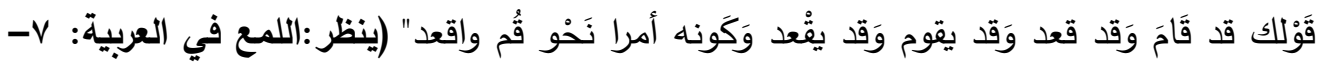

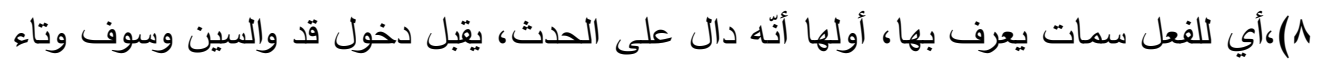
التأنيث الساكنة. وقد ذكر ابن مالك هذه العلامات في ألفيته قال:

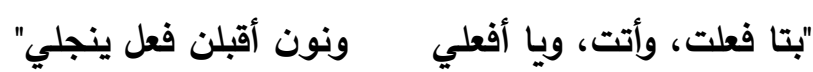

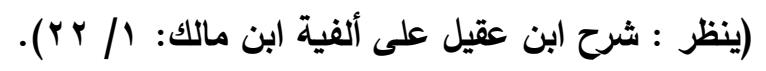

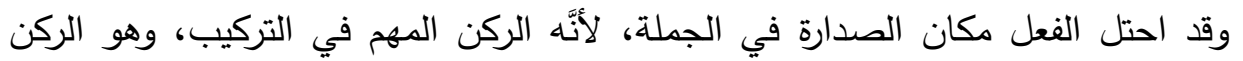

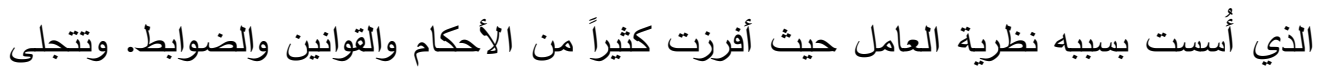

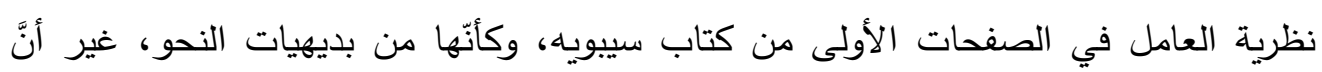

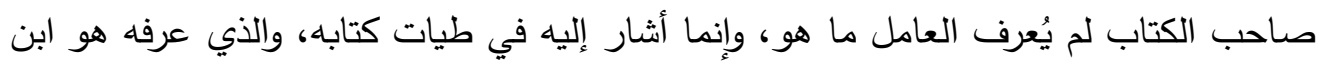

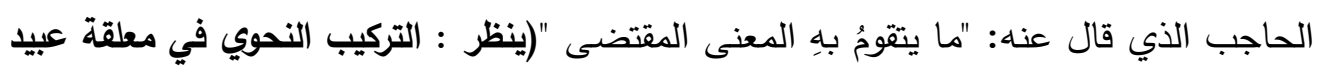

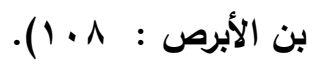
ويعرف تمّام حسّان الفعل فيقول: "حدث تعبر عنه الحروف الأصلية الثلاثة، وزمن يدل على الإنى

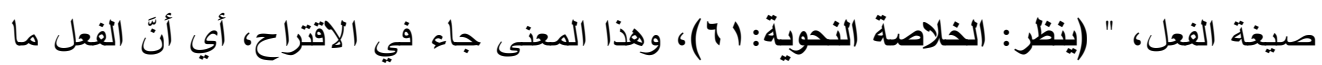


دل على الحدث بلفظه، وعلى الزمن بصيغته، ولذلك تختلف الدلالة على الزمن باختلاف دلالة الصيخ، ولا تختلف دلالة الحدث بصيغتها (ينظر : الخلاصة النحوية: الج). ويقسم الفعل بعدة اعتبارات، من حيث مادته الى معتل وصحيح، وما يختص بتصريفه

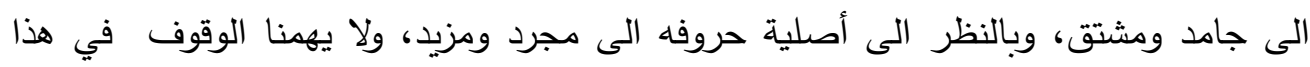

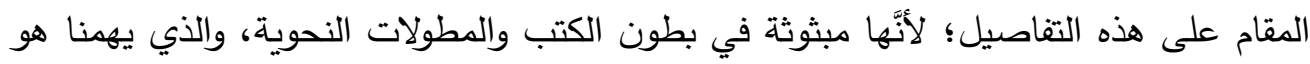

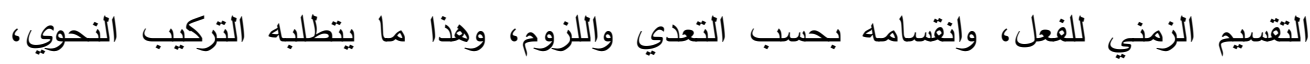

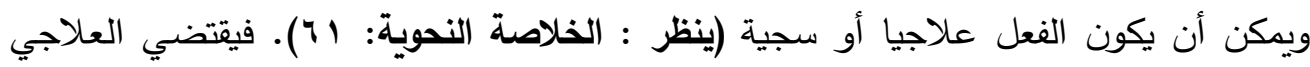

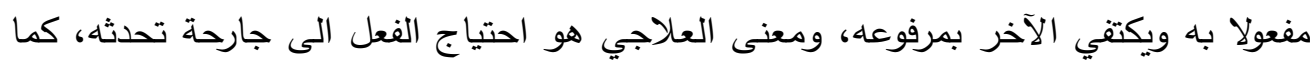

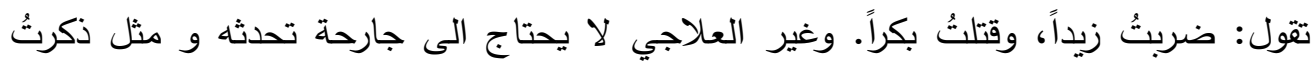

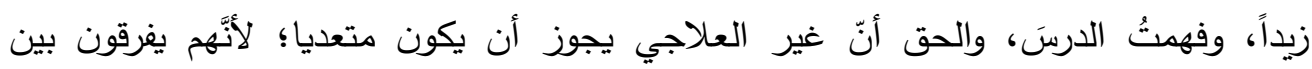

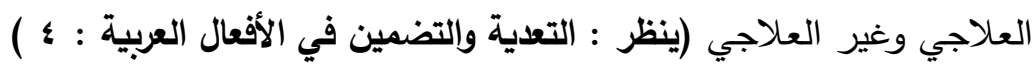

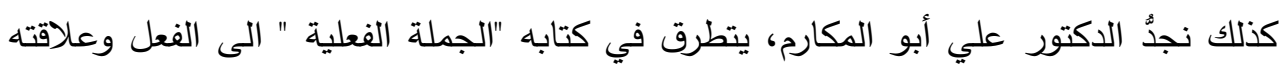

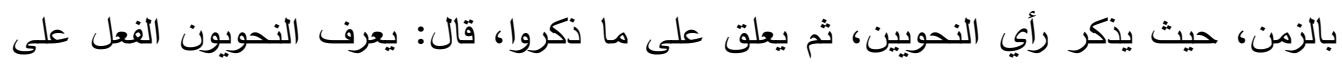

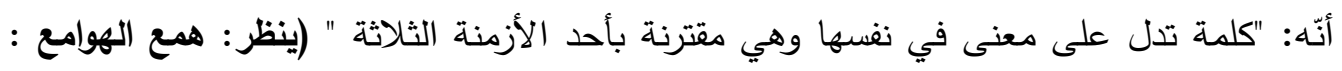

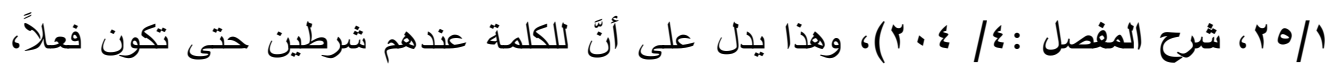

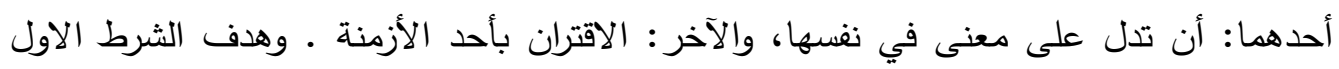
إخراج الحروف؛ لأنَّها لا تدلّ على معنى في نفسها، وغاية الثرط الثاني إخراج الأسماء؛ لأنَّها

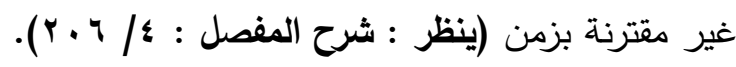

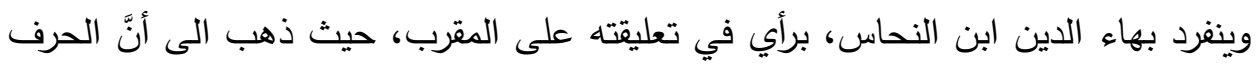

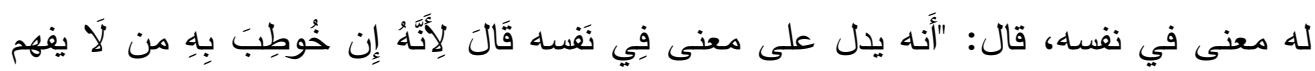

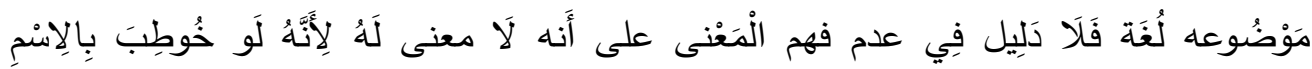

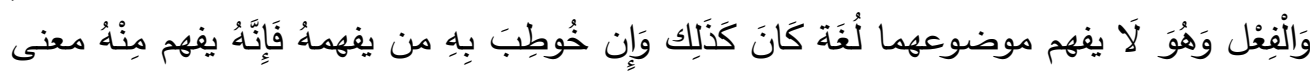

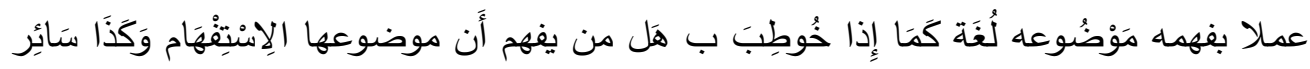

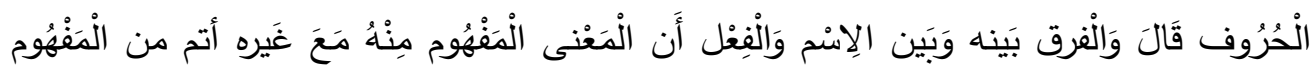

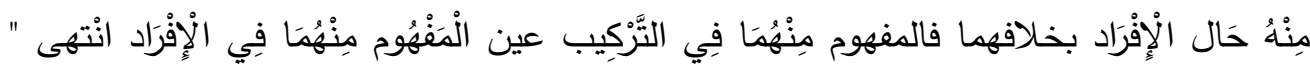

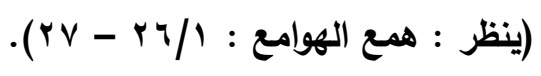


وهذا الذي قد يكون من المسلمات اللغوية، أي أنَّ الفعل هو الكلمة التي تدلّ على معنى

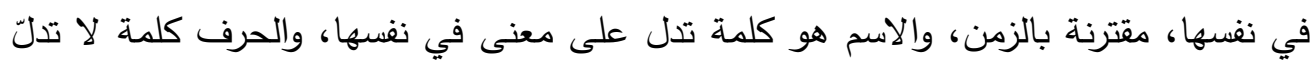

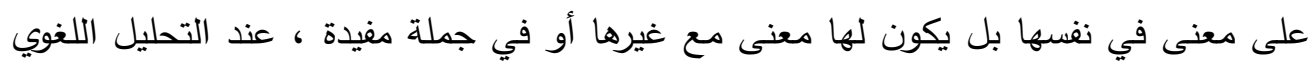

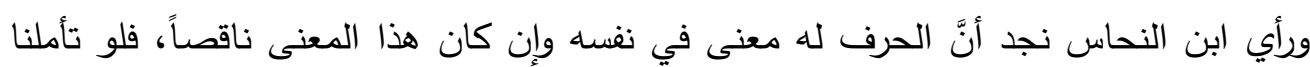

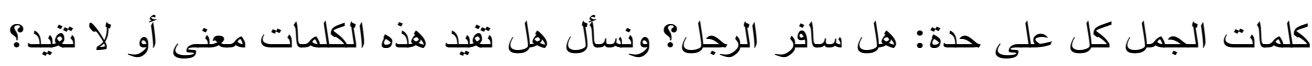

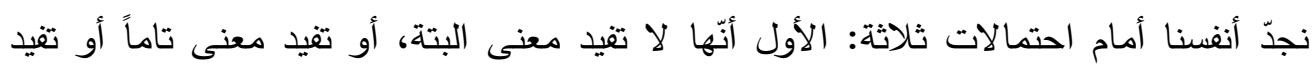

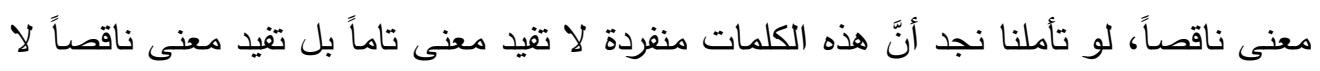

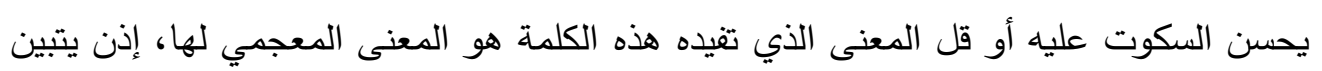

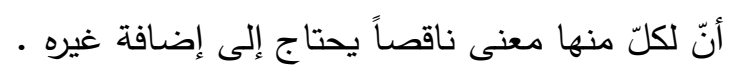

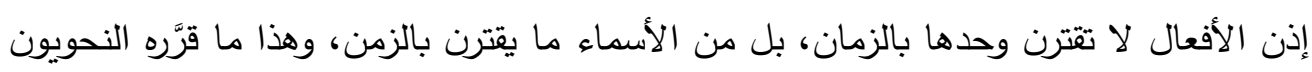

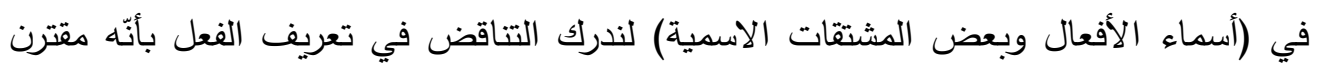

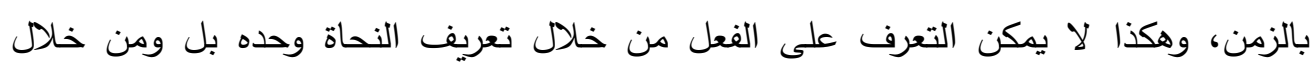
العلامات التي تميزه عن غيره وتلك العلامات التي ذكرها ابن مالكات في ألفيته :

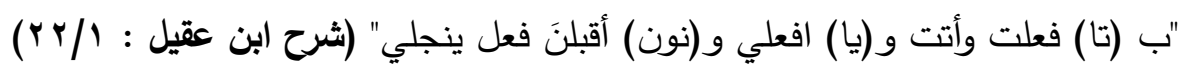

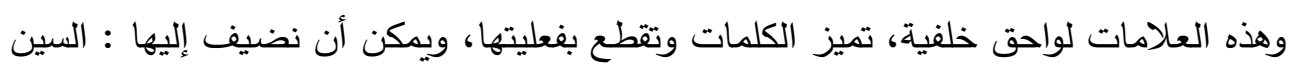

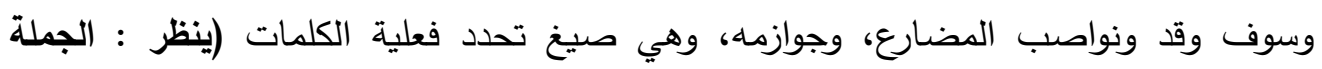
الفعلية : ب ؟ - ـ ؟ ). ب- الفاعل :

لم نجدّ في القرون الأولى الهجرية، تعريفاً واضحاً للفاعل إلا حكمه، والفاعل هو أصل : الصل المرفوعات وما عداه هو ملحق به (ينظر : اللباب في علم الإعراب : ج111).

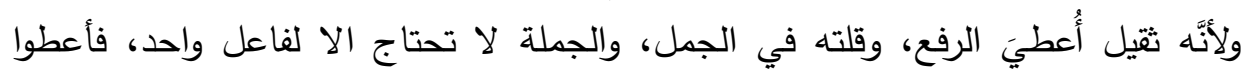

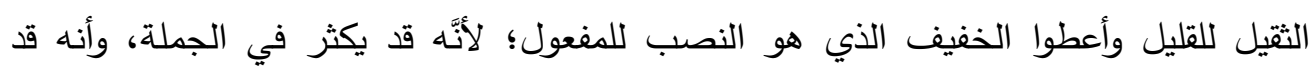
يتعدى الى أكثر من مفعول (ينظر: أصائة النحو العربي : 91).

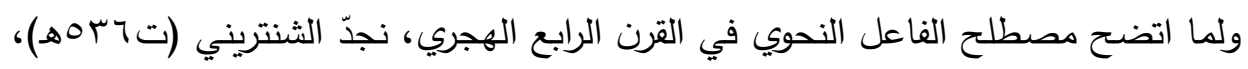

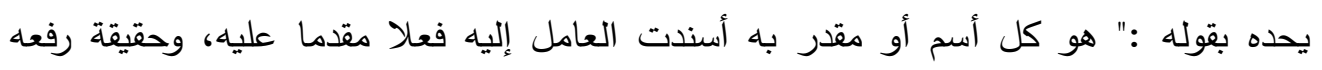

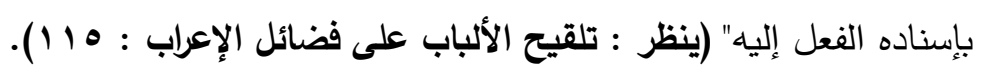


فالفاعل على ما تقدم هو: اسم أو ما في تأويله، أسند إليه فعل تام أو ما في تأويله، مقدم أصلي المحل والصيغة (ينظر : كثف النقاب عن مخدرات ملحة الإعراب : 9 ه ـ 1).

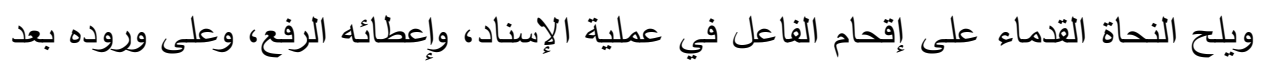

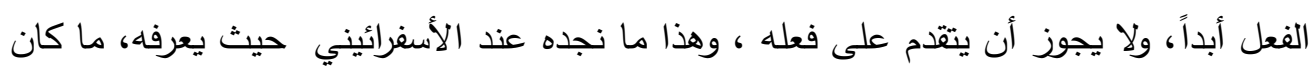

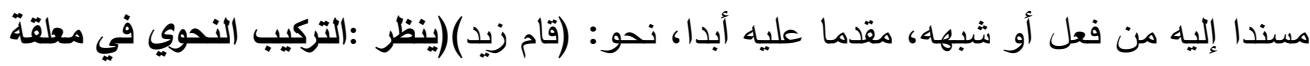

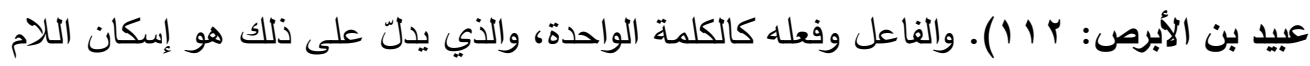
في نحو: (ضربْتُ)، لذا قالوا يجب أن يتأخر عن فعله (ينظر : اللباب في علم الإعراب : ؛ ؛).

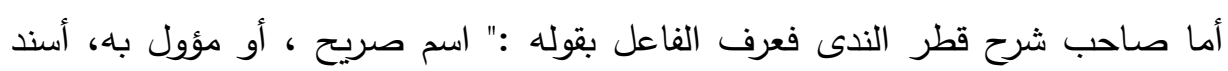

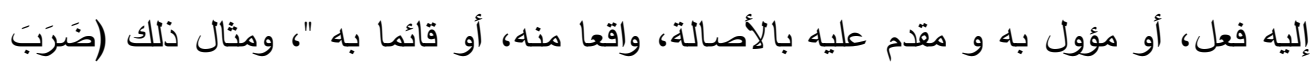

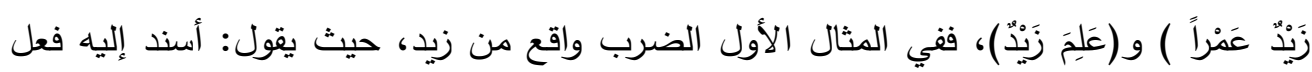

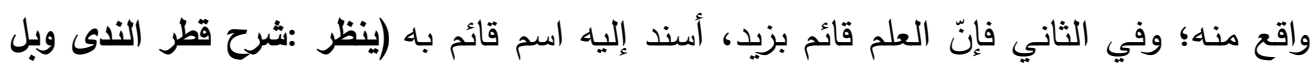

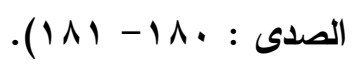

أمّا الصور التي يأتي فيها الفاعل في الجملة، فيأتي تارة اسما ظاهرا صريحا، وطورا

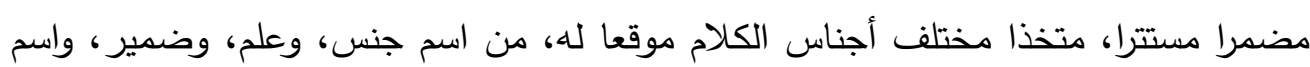

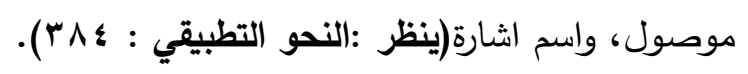

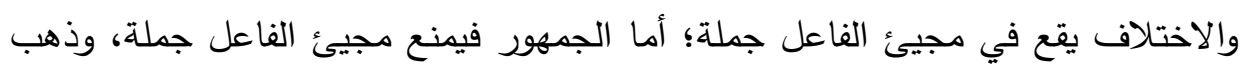

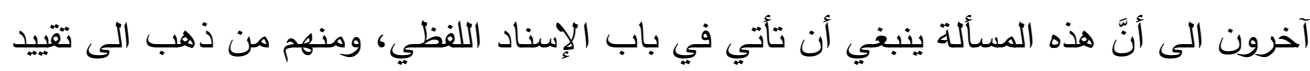

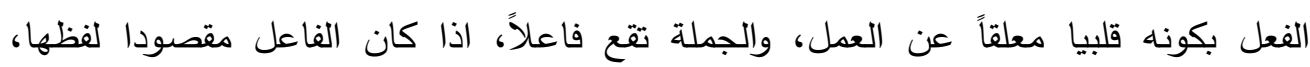

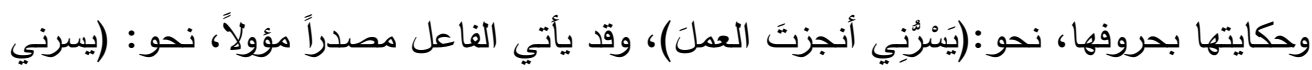
أن أن تنوق)

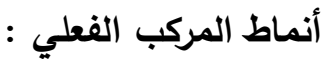

المركب الفعلي هو المركب الذي يبدأ بالفعل، أو المسند فيه فعل، سواء تقدم هذا الفعل

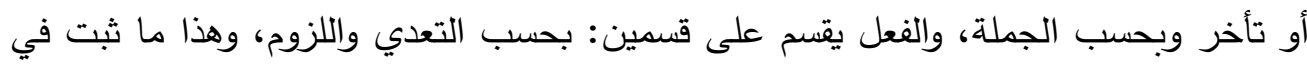

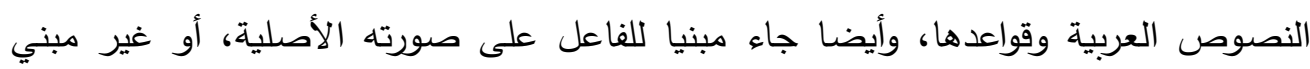

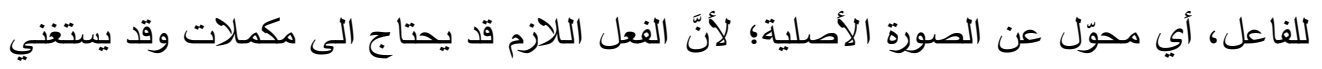
عنها، أما المتعدي فأنّه يحتاج إلى مكملات من مفاعيل أو غيرها، لإتمام معنى الجملة. 
أما الأشكال النمطية للمركب الفعلي، وبحسب قواعد اللغة العربية المختصة بالجملة الفعلية، من تعجب وتعد ولزوم وحذف وتقديم وتأخير في أركان الجملة، فيكفي أن نحيل فيها

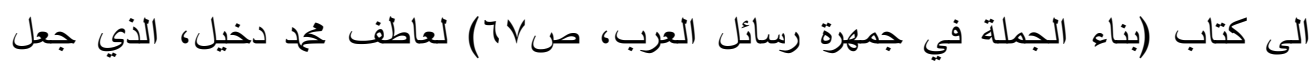

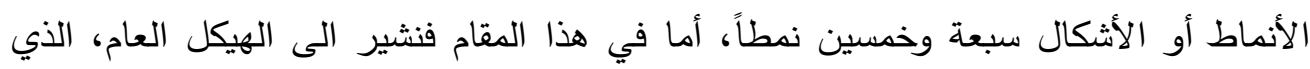

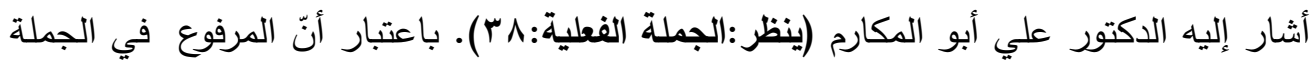

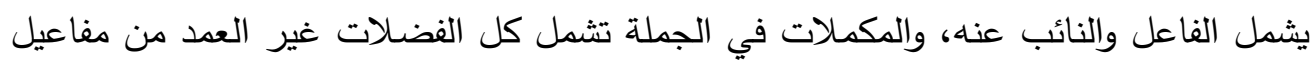
وغيرها في الجمل، أما الأشكال بحسب الهيكل العام فهي أربعة العيكة :

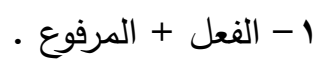

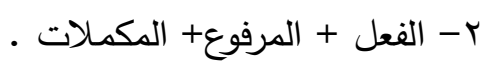

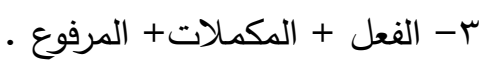

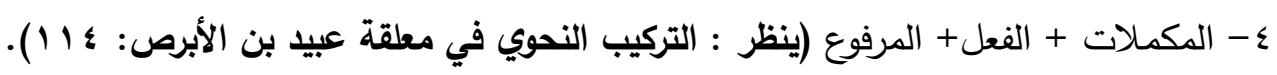

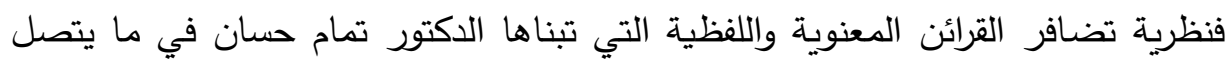

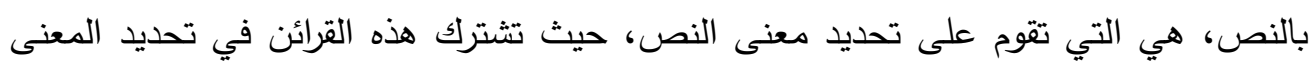
المطلوب (ينظر : التركيب النحوي في معلقة عبيد بن الأبرص: . ب ب).

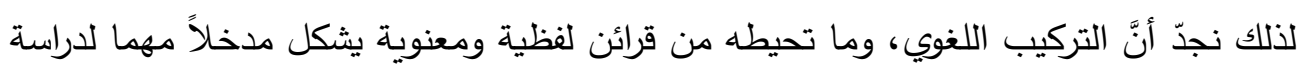

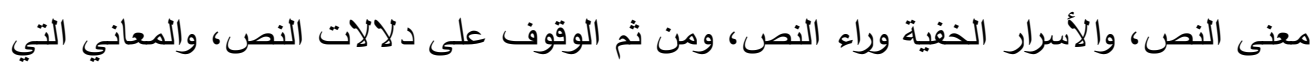

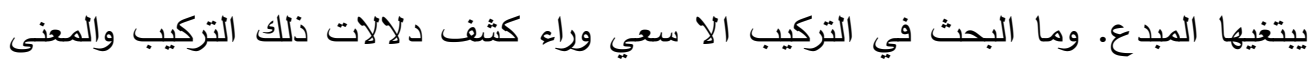

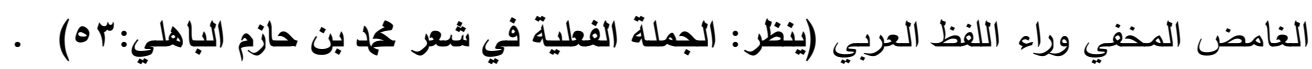

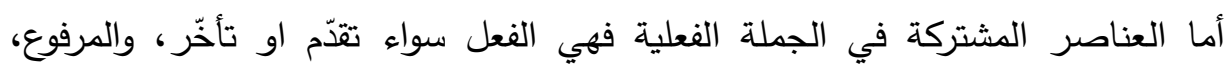

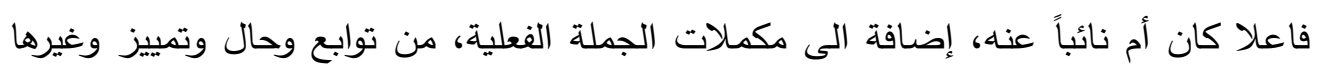

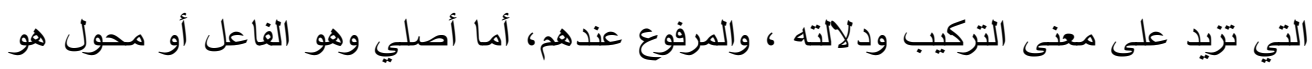

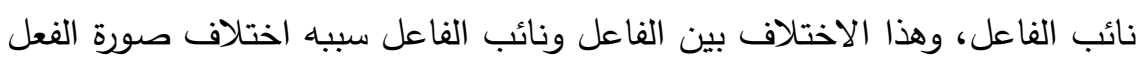

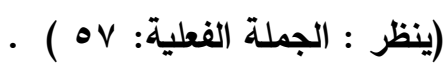
ونمثل لبعض أنماط التركيب الفعلي من لغة الثخصيات عند نجيب الفيب محفوظ، ونتلمس أثر الاستعمال لتلك التراكيب، ومن ذلك:

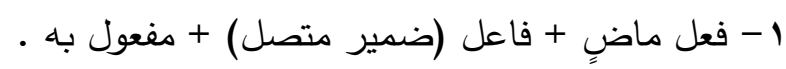
- "زرت سيدتك، وزرت سيدك ".....(السكرية م. • ب). 
نرى تكرار التركيب الفعلي من قبل أمينة في معرض الدفاع عن نفسها لمّا لامها السيد،

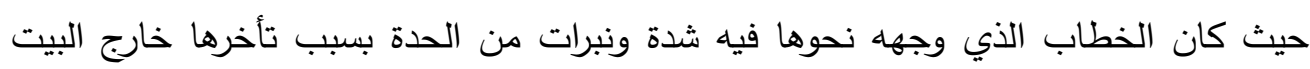

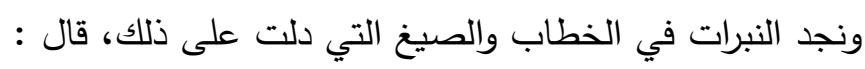

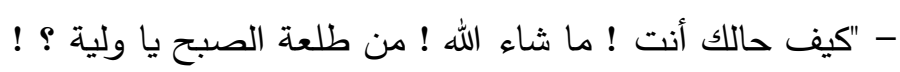
فابتسمت قائلة :

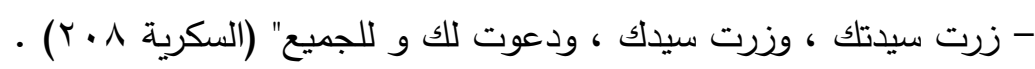

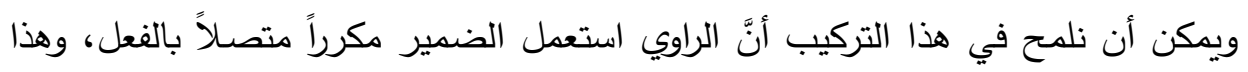

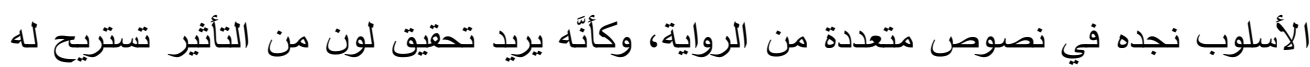

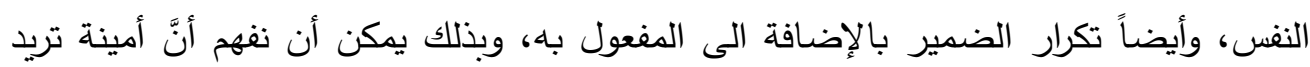

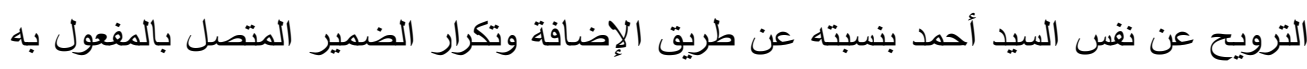

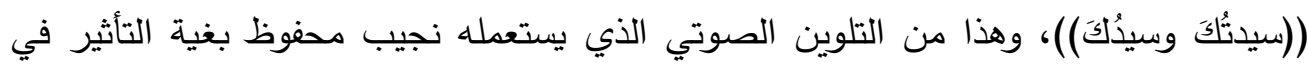

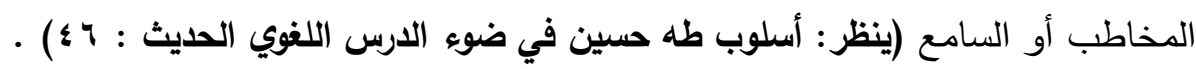
r - فعل مضارع + فاعل (ضمير مستتر) + مفعول به (مصدر مؤول من أن والفعل) .

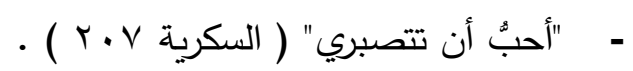

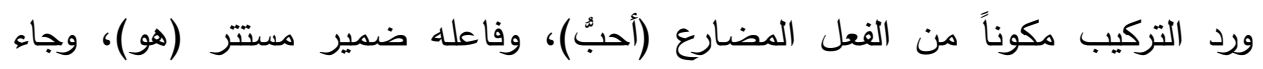

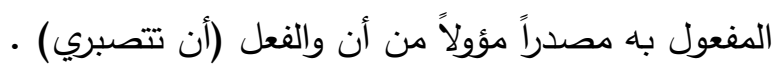
r- فعل مضارع + فاعل ضمير مستتر + مصدر مؤول (أن والفعل) .

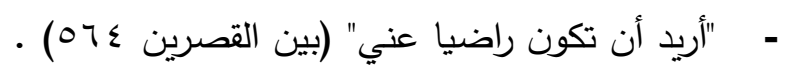

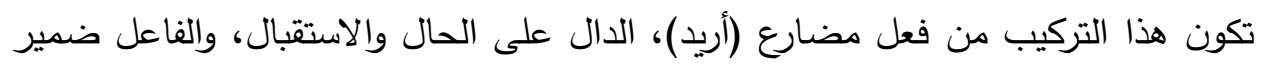

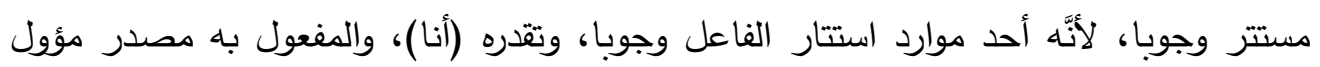

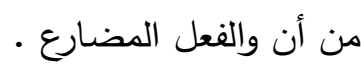
ع - فعل ماضٍ + فاعل (لفظ الجلالة علم) + مفعول به (جملة اسمية) .

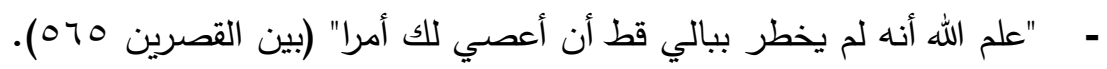

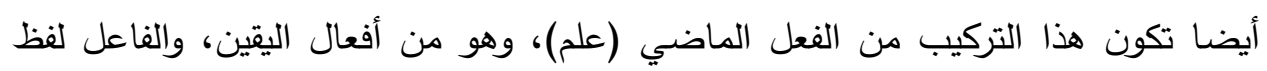

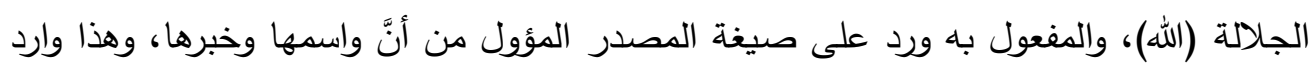

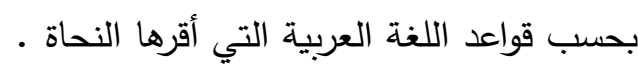
ه- فعل ماضي + فاعل (معرف بال) . 


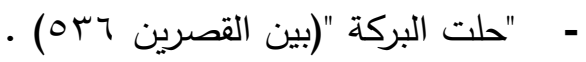

تكونت هذه الصيغة التركيبية من الفعل (حلَّ) المتصل بتاء التأنيث اشارة الى أنَّ الفاعل

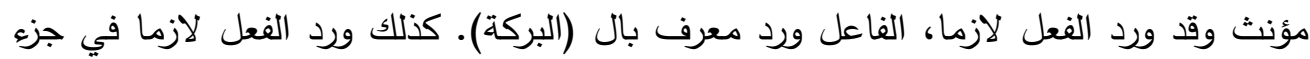
السكرية، والجملة بسيطة خالية من المكملات، كما في الجمل الآتية : צ- الفعل المضارع + مفعول به (ضمير متصل) + الفاعل (مصدر مؤول من أن والفعل).

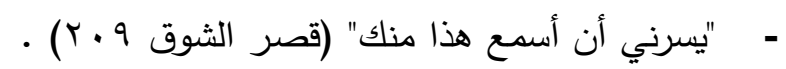

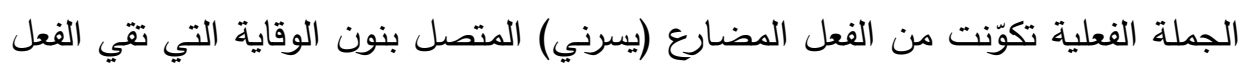

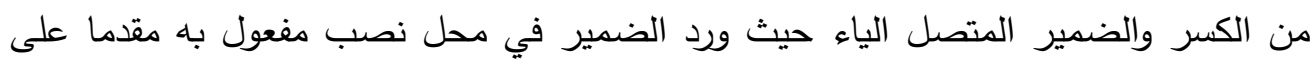

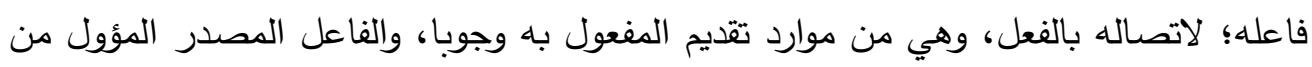

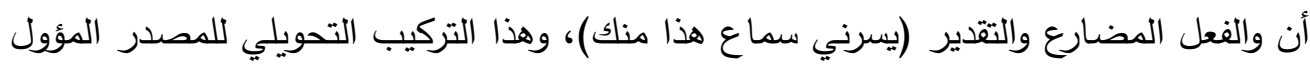

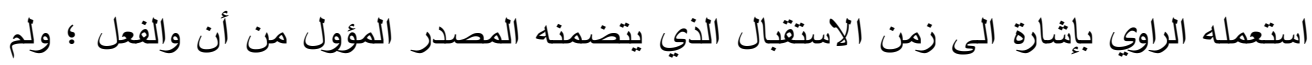

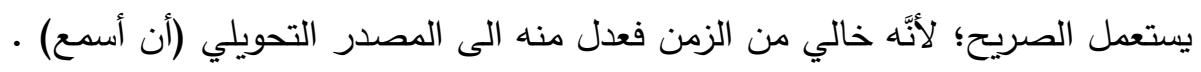

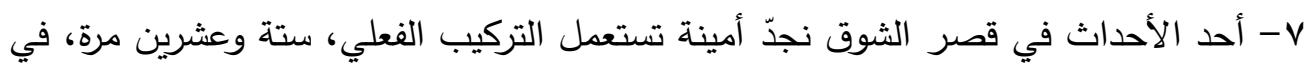

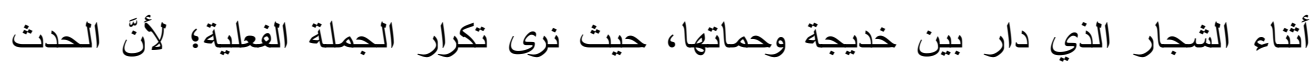

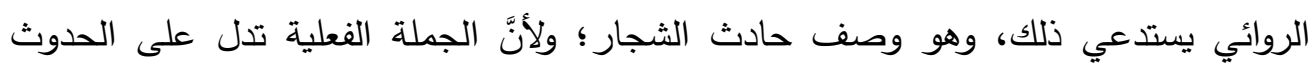

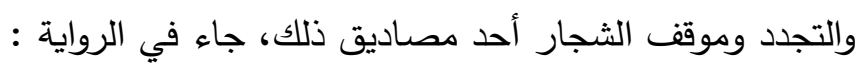

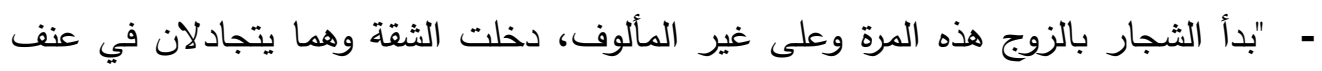

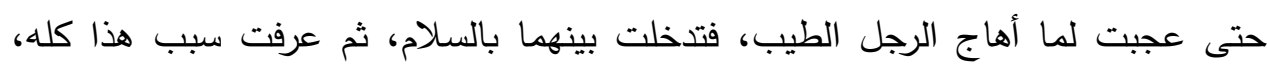

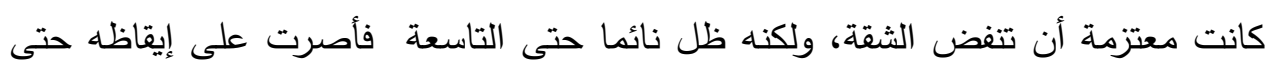

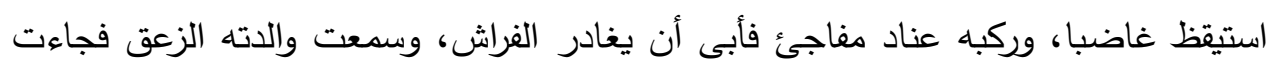

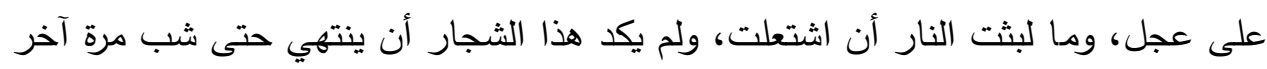

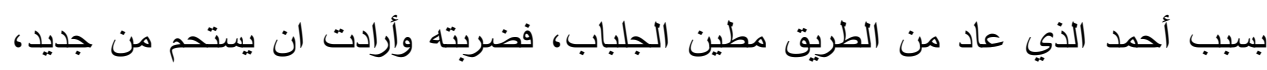

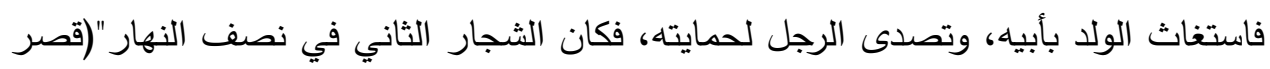

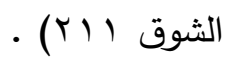

نجد أنَّ موقف الثجار الذي يقع دائما بين خديجة وحماتها جعل الأديبت يستعمل

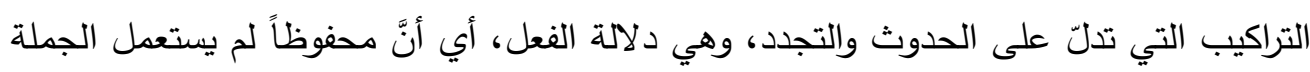

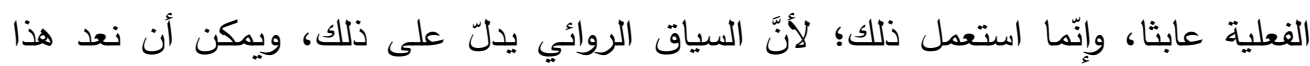




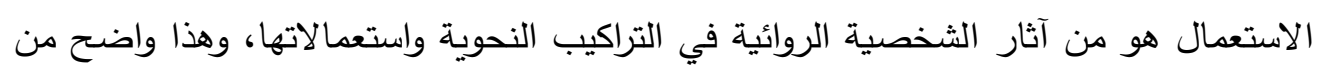

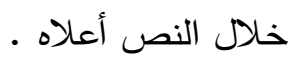
^- موقف آخر من قصر الثوق تستعمل الثخصية التركيب الفعلي، في موقف الثجار الذي نشب بين أمينة وياسين؛ بسبب خطبة ياسين لمريم بنت الجار مححد رضوان، جاء في الرواية:

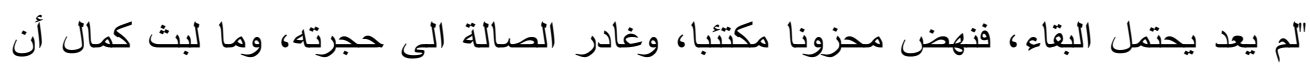
لحق به ولم يكن دونه حزنا وكآبة فقال:

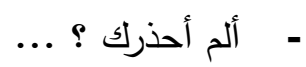
فقال ياسين مقطبا: - لن أبقى في هذا البيت دقيقة واحدة بعد الآن ..!

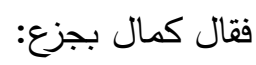

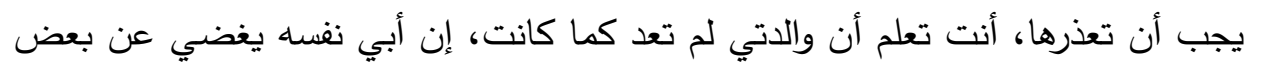

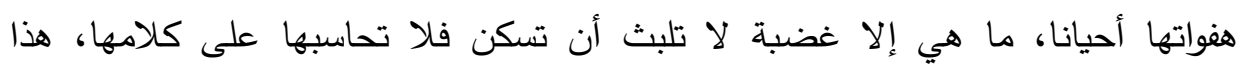

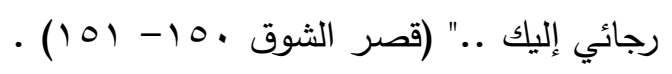

نرى تكرار الجمل الفعلية في هذا الحوار الروائي؛ لأنَّ الحدث يستدعي التغير التئ والحركة

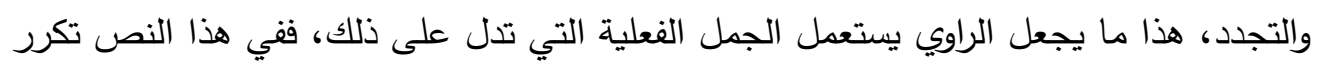

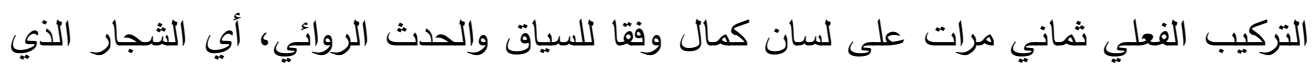

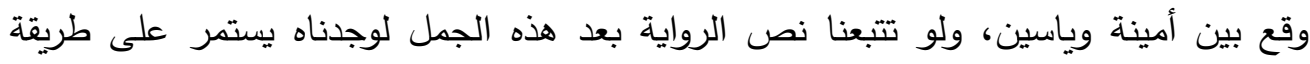

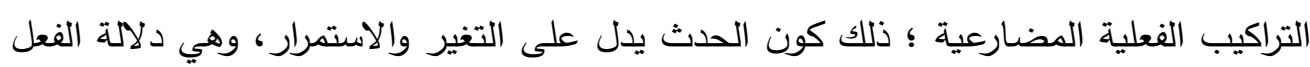

$$
\text { • المضارع }
$$

9- في سياق نص حواري يجمع بين كمال وياسين في ولادة نعيمة، الولادة الخطرة القلقة

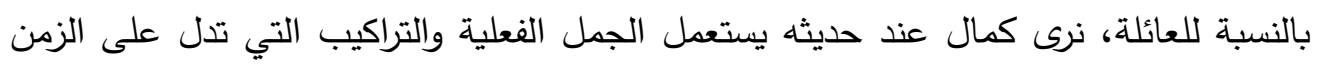

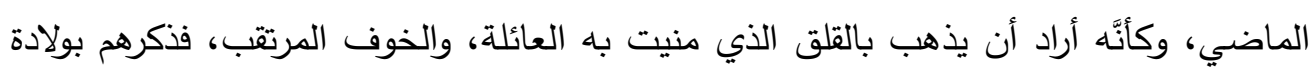

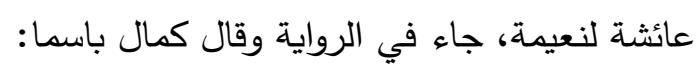

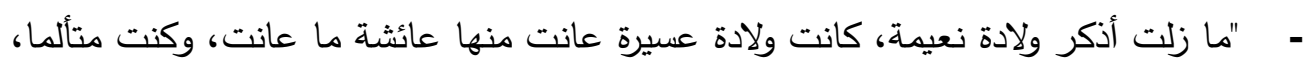
وكنت واقفا في هذا المكان مع المرحوم خليل".(السكرية عم (1) ). 
الثّّخصية تستعمل التراكيب التي فيها دلالة على الماضي، وكأنَّ كمال يريد أن يُطمئن

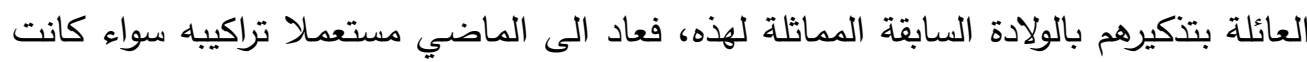

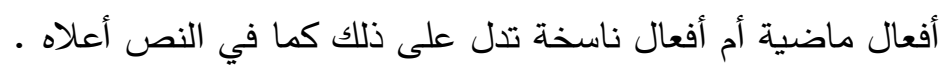

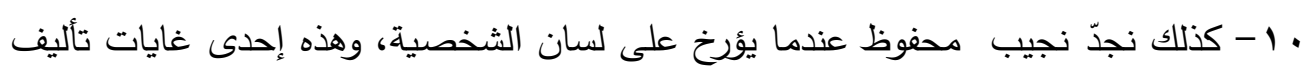

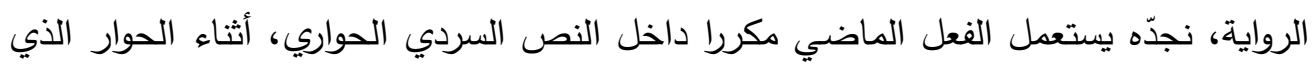

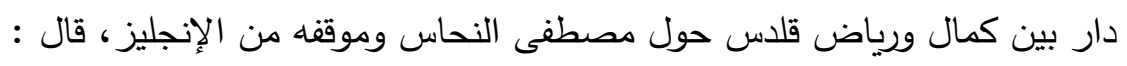

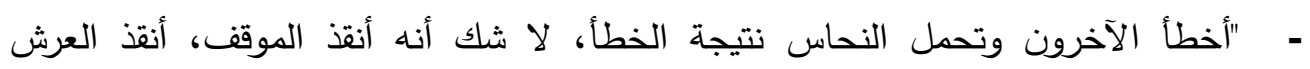

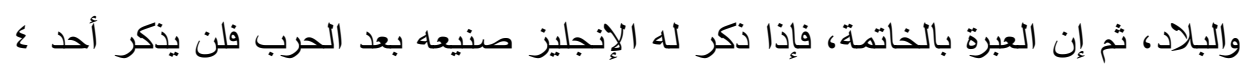

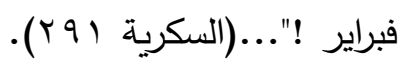

هنا يستعمل محفوظ الفعل الماضي ست مرات، في حين استعمل التركيب الاسمي ثلاث

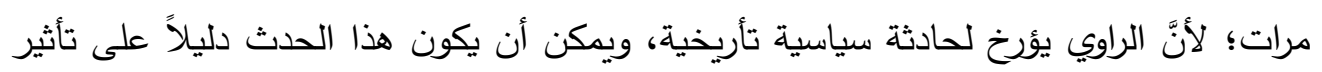

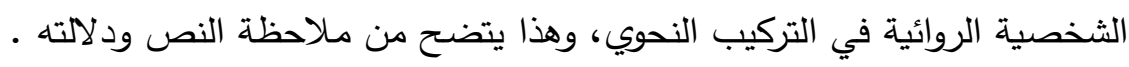

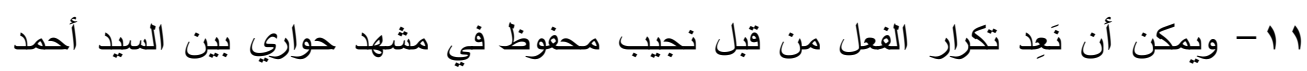

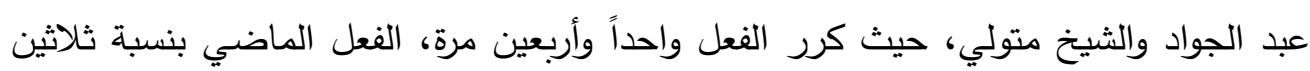

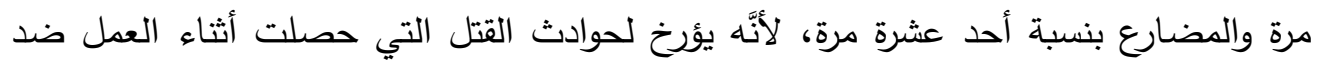

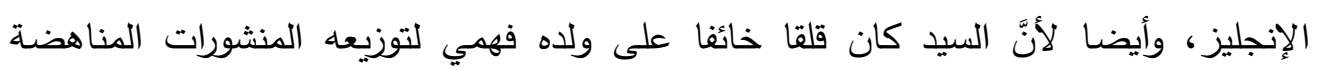

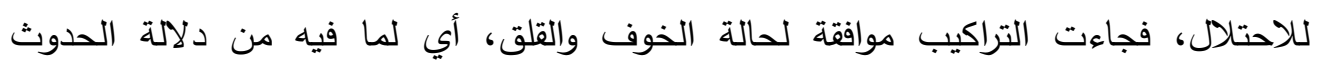
والتجدد، وهذا تأثير واضح على التركيب النحوي وبحسب الموقف والحدث الروائي، جاء في النص: - لقد ضاع ابن الفولي اللبان في غمضة عين فشهد مأتمه معي وعزّى والده المسكين، كان الثاب يوزع سلاطين اللبن الزبادي فصادف في طريقه مظاهرة فأغراه القضاء" .........

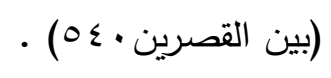

r T - وفي مشهد بين القصرين رقم (TV)، نلاحظ أنَّ الأديب يساوي بين الفعل الماضي

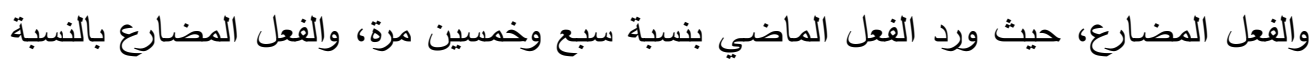

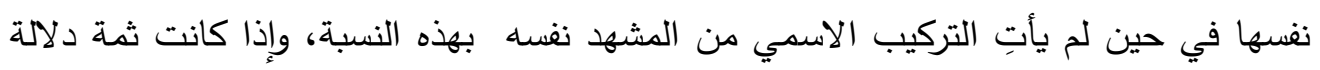

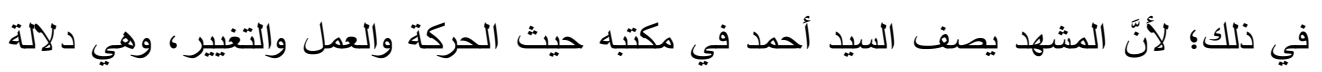

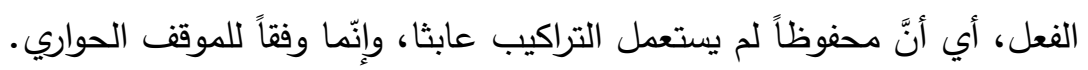


rا - كذلك في نص آخر من جزء بين القصرين نجد أنَّ الفعل يتكرر عشرَ مرات؛ لأنَّ

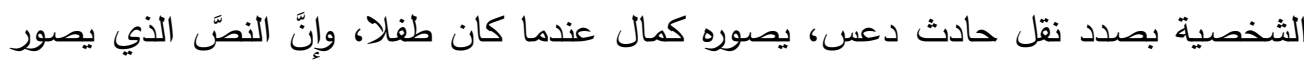

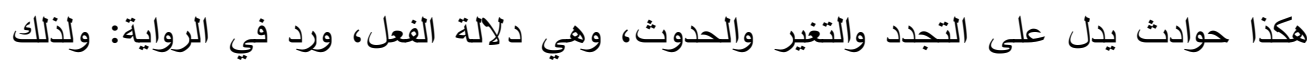

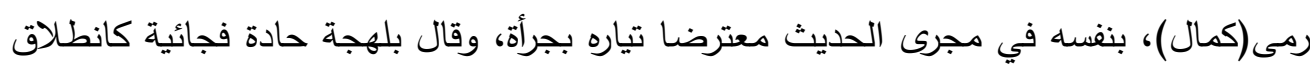

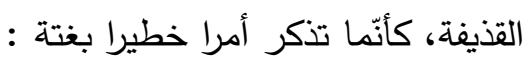

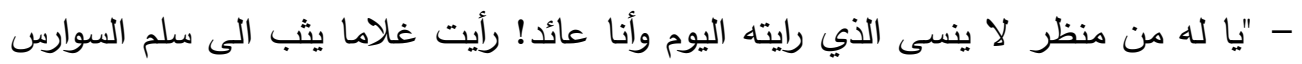
ثم صفع الكمساري وركض بأكبر سرعة فما كان من الرجل إلا أن عدا وراءه حتى أدركه ثن

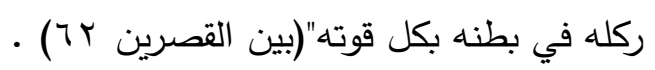

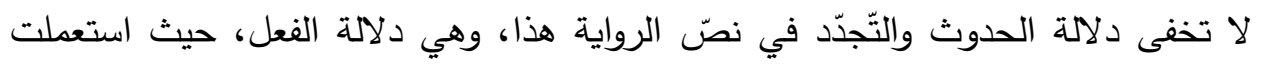

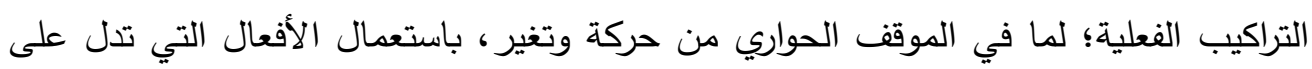

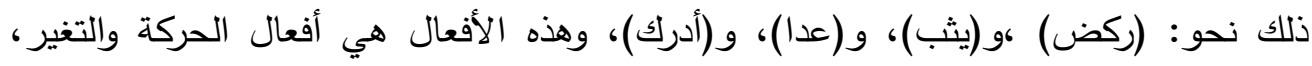

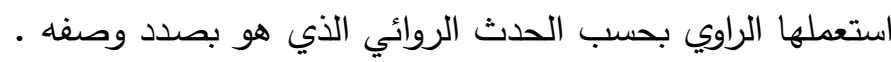

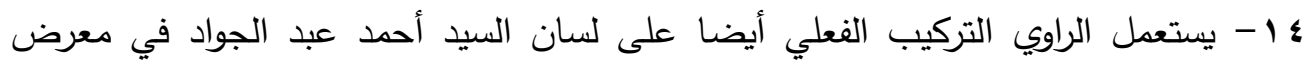

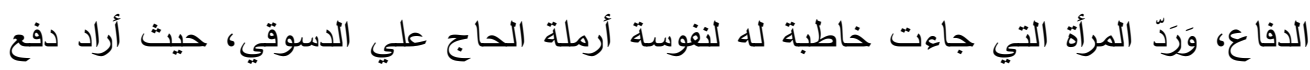
ذللك المشروع، قال: " لقد تزوجت مرتين، أخفقت في الأولى ووفقني الله في الأخرى، ولن أبطر النه النه

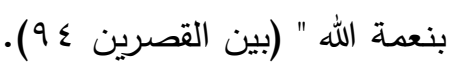

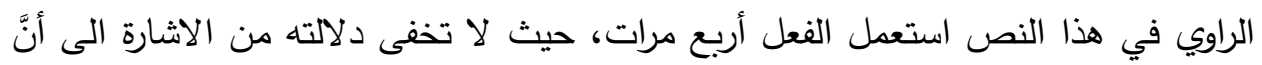

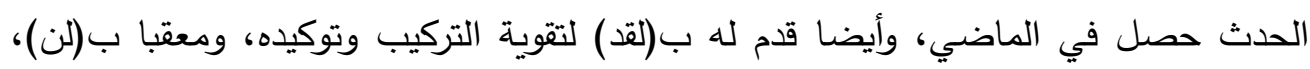

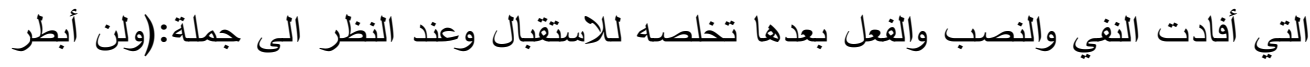

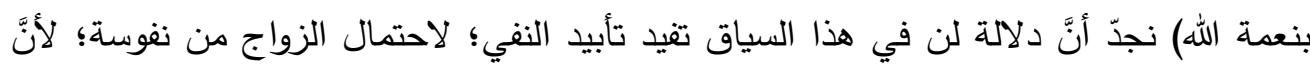

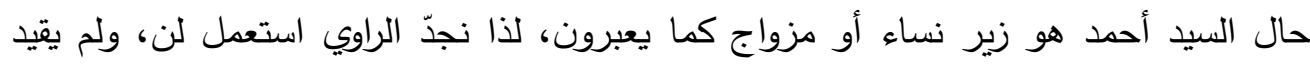

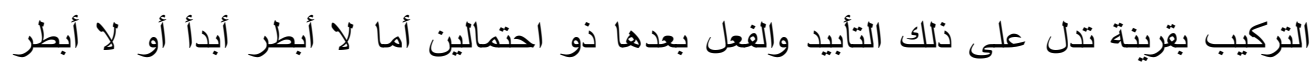

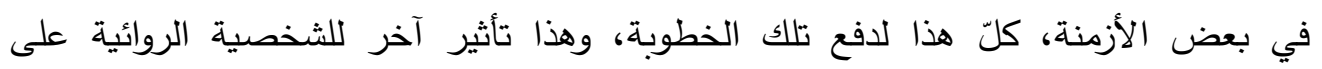
التركيب النحوي، أي أنَّ الراوي يختار التركيب وفقا للحدث السردي وظروف الثخصية. 
نجد أنَّ الكثرة في استعمال التركيب تُعبر عن غزارة الأحداث وتعدد المواقف داخل المشهد الروائي، والقلة في استعمالها تدل على ميل الكاتب للإيجاز والبساطة في بعض التراكيب. وهذا يدل على قدرة محفوظ اللغوية وثراءه الأسلوبي، وشغفه بسرد الأحداث ودقة الوصف. ويمكن أن يُعد هذا التفاوت في الاستعمال التركيبي كثرة وقلة من أثر الثخصية الروائية في التركيب النحوي. وبهذا يتضح أن محفوظ استعمل التركيب الفعلي بنسبة أكثر من التركيب الاسمي وهو ما درجت عليه اللغة العربية في الاستعمال الفعلي. وإنَّ الأديب محفوظ يستعمل التركيب الفعلي في المواقف التي تدل على الحركة والتغير وهي دلالة الفعل.

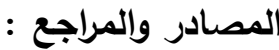

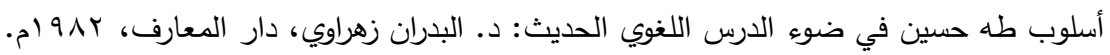

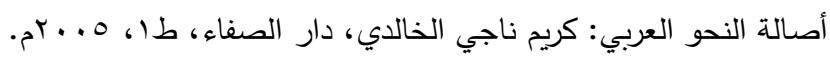

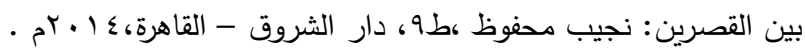

التعدية والتضمين في الأفعال العربية: عبد الجبار توامة، ديوان المطبوعات الجامعية، ـو 99 ام، الجزائر .

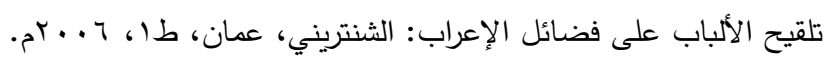

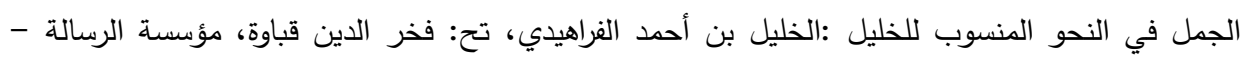

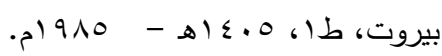

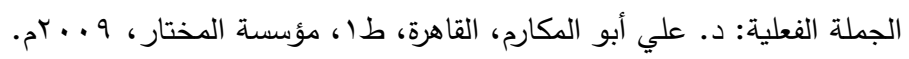

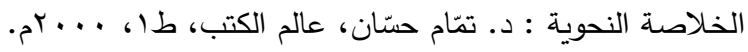

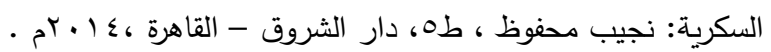

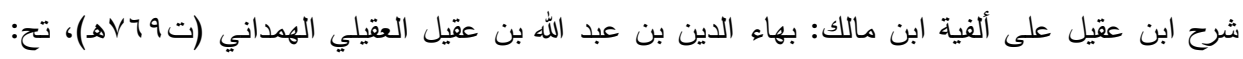

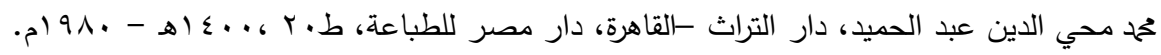

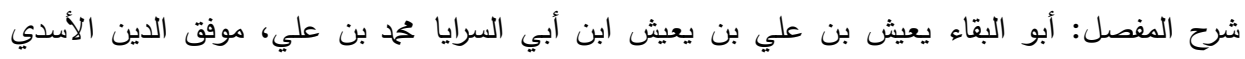

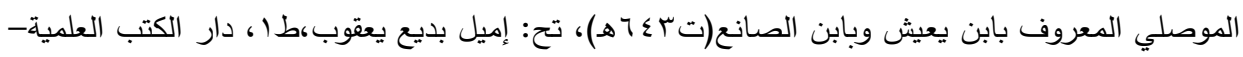

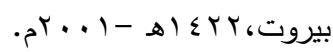
شرح قطر الندى وبل الصدى: عبد الله بن يوسف بن أحمد بن عبد الله بن يوسف، أبو محمد جمال الدين،

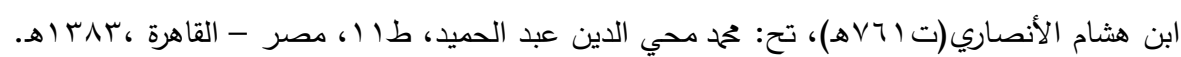

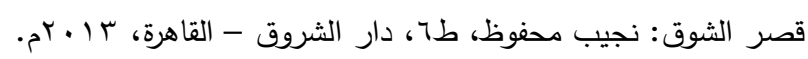

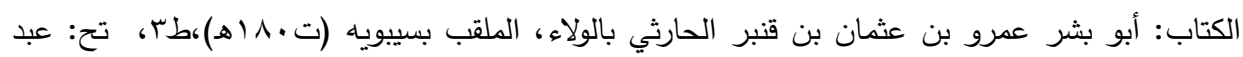

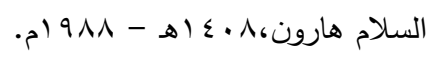


